\title{
Correction to: Stocking density alters growth performance, serum biochemistry, digestive enzymes, immune response, and muscle quality of largemouth bass (Micropterus salmoides) in in-pond raceway system
}

\author{
Julin Yuan • Meng Ni • Mei Liu • Jianfeng Lou • \\ Guoqiang Mi $\cdot$ Zhimin Gu (D)
}

Published online: 19 August 2021

(C) Springer Nature B.V. 2021

\section{Correction to: Fish Physiology and Biochemistry}

https://doi.org/10.1007/s10695-021-00948-3

The original version of the article unfortunately contained an error.

The order of authors in the online version was different from the proof version. The correct author name is shown below.

Julin Yuan ${ }^{1}$ (first author), Meng $\mathrm{Ni}^{1}$, Mei Liu ${ }^{1}$, Jianfeng $\mathrm{Lou}^{2}$, Guoqiang $\mathrm{Mi}^{1}$, Zhimin $\mathrm{Gu}^{1}$ (corresponding author).

Publisher's note Springer Nature remains neutral with regard to jurisdictional claims in published maps and institutional affiliations.

The original article can be found online at https://doi.org/ 10.1007/s10695-021-00948-3.

J. Yuan · M. Ni · M. Liu · G. Mi · Z. Gu ( ()

Zhejiang Institute of Freshwater Fisheries,

Huzhou 313001, China

e-mail: guzhimin2006@163.com

J. Lou

Nanxun Fishery Technical Extension Center,

Huzhou 313002, China 